\title{
Governo eletrônico no Rio Grande do Norte: uma avaliação de prefeituras municipais a partir de lei de acesso à informação
}

\section{Camila Cristina Rodrigues Salgado}

\begin{abstract}
Mestre em Engenharia de Produção e Doutoranda pelo Programa de Pós-Graduação em Administração da Universidade Federal do Rio Grande do Norte (PPGA/UFRN).
\end{abstract}

Renan Felinto de Farias Aires

\begin{abstract}
Mestre em Administração e Doutorando em Administração pelo Programa de Pós-Graduação em Administração da Universidade Federal do Rio Grande do Norte (PPGA/UFRN). Professor do Departamento de Ciências Administrativas da Universidade Federal do Rio Grande do Norte DEPAD/UFRN.
\end{abstract}

http://dx.doi.org/10.1590/1981-5344/2707

No contexto do chamado Governo Eletrônico, no qual o poder público divulga serviços, informações, projetos e programas, por meio de portais eletrônicos, o Brasil, na intenção de garantir e promover a consolidação da transparência e democracia, promulgou em 2011 a Lei de Acesso à Informação (LAI), regulando o acesso à informação no país. Assim, considerando que a criação de uma legislação é apenas uma etapa na construção de uma política de transparência, este estudo de finalidade exploratório-descritiva objetiva avaliar a conformidade, em relação à $L A I$, dos sítios eletrônicos de prefeituras do Estado do Rio Grande do Norte (RN), utilizando-se da pesquisa bibliográfica como ferramenta de coleta de dados e da análise de conteúdo como técnica de análise dos dados. Como resultados, obteve-se que o governo eletrônico tem sido aplicado pelas prefeituras do $R N$ avaliadas, porém muitos avanços precisam ser realizados, tendo em vista algumas não conformidades identificadas.

Palavras-chave: Governo Eletrônico; Lei de Acesso à Informação; Rio Grande do Norte. 


\section{E-government in rio grande do norte: an evaluation of city councils from the access to information law}

In the context of so-called e-government, in which the government discloses services, information, programs and projects, through electronic portals, Brazil, in an attempt to ensure and promote the consolidation of transparency and democracy, enacted in 2011, The access to information law ( $L A I)$, regulating access to information in the country. So, considering that the creation of legislation is just one step in building a policy of transparency, this exploratory and descriptive study aims assess conformity in relation to LAI, city council's electronic sites of the Rio Grande do Norte state (RN), using the bibliographic research as a data collection tool and content analysis as the data analysis technique. As a result, it was found that e-government has been applied by the evaluated RN city councils, but many advances need to be made because of some non-compliances identified.

Keywords: Electronic government; The access to information law; Rio Grande do Norte.

Recebido em 10.02.2016 Aceito em 11.04.2017

\section{Introdução}

O crescimento dos serviços eletrônicos, a abertura de canais de comunicação com a sociedade e a divulgação de iniciativas da administração pública são aspectos que têm sido facilitados por meio do desenvolvimento tecnológico (LAIA et al., 2011). Nesse contexto, governos de diferentes países têm operado de forma a se adaptarem às novas realidades na era do conhecimento, na qual se molda uma sociedade da informação em que as Tecnologias de Informação e Comunicação (TIC) têm papel crucial no modo como o Estado cumpre suas principais funções (MEDEIROS; GUIMARÃES, 2006).

As novas tecnologias têm oferecido inúmeras possibilidades de procedimentos administrativos democráticos e públicos, sendo mais eficientes e acessíveis, dando assim origem ao Governo Eletrônico, que tem implicações mais amplas para a governança e a democracia (SISKOS; ASKOUNIS; PSARRAS, 2014). 
De forma geral, o governo eletrônico refere-se à utilização de tecnologias de informação e comunicação por órgãos do governo para transformar as relações com os cidadãos, empresas, e organizações do governo, o que representa uma das evoluções mais relevantes e importantes para a administração pública (LUPU; LAZAR, 2015). Essa é uma iniciativa essencial pelo seu potencial de promoção de práticas democráticas, permitindo relacionamentos mais eficientes entre governo e os cidadãos (CUNHA; MIRANDA, 2013).

Nesse cenário, o governo eletrônico tem ampliado o caminho para a transparência por parte dos governos, além de modernizar os serviços prestados, proporcionando maior interação e democratização na relação entre o cidadão e o governo, algo que ganha força quando se leva em conta a importância dentro da sociedade informacional (OLIVEIRA; RAMINELLI, 2014). Sobre isso, sabe-se que as amplas possibilidades de difusão da informação e de incremento de formas de participação da sociedade civil levaram diferentes teóricos a afirmarem que uma nova expressão de cidadania, mais ativa e participativa, está emergindo nessa nova era (SILVA; RUE, 2015).

Como resultado dessa nova realidade, o Brasil vê surgir a necessidade de garantir e promover a consolidação da transparência e democracia, o que fez com que, em novembro de 2011, fosse promulgada a Lei de Acesso à Informação que, em síntese, trata da obrigação da disposição de informações na rede sobre a estrutura, funcionamento e prestação de contas dos órgãos/entidades da administração direta e indireta, e de todos aqueles que recebem subvenção pública (BERNARDES; SANTOS; ROVER, 2015).

A academia tem mostrado interesse e concentrado alguns esforços na intenção de avaliar de alguma forma como a Lei de Acesso à Informação vem sendo aplicada, o que permite citar alguns estudos, como: o de Santos et al. (2013), que objetivou verificar em qual estágio de evolução encontram-se os sites governamentais dos tribunais de contas brasileiros; o de Bernardes, Santos e Rover (2015), que analisou como a Lei de Acesso à Informação está sendo implementada pelas prefeituras da região Sul do país; o de Raupp e Pinho (2014), que investigou a prestação de contas nos portais eletrônicos de Assembleias Legislativas após a Lei de Acesso à Informação entrar em vigor; o de Oliveira e Raminelli (2014), que faz uma análise da página do Conselho Nacional de Justiça no Facebook; e o de Cavalcanti, Damasceno e Souza Neto (2013), que analisa a conformidade dos sítios eletrônicos das autarquias federais em relação à Lei de Acesso à Informação.

Diante do exposto, e considerando que a criação de uma legislação é apenas uma etapa na construção de uma política de transparência no país, já que a norma deve ser transformada em ações e fatos (PAES, 2011), o presente trabalho objetiva contribuir com a exploração dessa área, avaliando a conformidade, em relação à Lei de Acesso à Informação, dos sítios eletrônicos de prefeituras do Estado do Rio Grande do Norte. 
Para tanto, o artigo está estruturado da seguinte forma: em primeiro lugar discute sobre os principais conceitos envolvidos em relação ao Governo Eletrônico e à Lei de Acesso à Informação, breves considerações acerca dos temas; em seguida apresenta-se o método do estudo; depois é apresentada a análise dos resultados; e, finalmente, tece as considerações finais, relatando as principais inferências.

\section{Revisão da literatura}

\subsection{Governo eletrônico: breves discussões}

O desenvolvimento tecnológico tem apoiado as atividades empresariais e governamentais em várias perspectivas (OLIVEIRA; RAMINELLI, 2014; SARRAYRIH; SRIRAM, 2015). Em meio ao desenvolvimento, avançam políticas do chamado Governo Eletrônico, que implica na utilização de portais pelo poder público, valendo-se de páginas na internet para divulgar tanto serviços quanto informações sobre sua atuação, seus projetos e programas (SILVA; RUE, 2015).

Em termos de conceito, o governo eletrônico refere-se à utilização de tecnologias de informação e comunicação (TIC), por parte dos governos, para prestar serviços digitais aos cidadãos e às empresas através da internet, a nível local, nacional ou internacional (MEDEIROS; GUIMARÃES, 2006; LUPU; LAZAR, 2015; SISKOS; ASKOUNIS; PSARRAS, 2014). Isso acarreta na revisão e integração de processos, para melhorar a eficiência e eficácia da administração pública, assim como para a criação de mecanismos de relações digitais com o cidadão (LAIA et al., 2011).

Além de ser uma das principais formas de modernização do Estado, o governo eletrônico, também conhecido como e-gov, está fortemente apoiado em uma nova visão do uso das tecnologias para a prestação de serviços públicos, mudando a maneira pela qual o governo interage com o cidadão, empresas e outros governos, viabilizando um novo modelo de gestão pública (DINIZ et al., 2009). Nesse modelo, as tecnologias de informação são usadas para operacionalizar e por em prática as transformações almejadas pelo "Novo Serviço Público", que tem um foco nas modificações no relacionamento do governo (OLIVEIRA; RAMINELLI, 2014), considerando que cidadãos, empresas e demais organizações querem ter acesso ao governo de modo cada vez mais rápido e facilitado, na expectativa de que os programas governamentais estejam focados em suas necessidades (MEDEIROS; GUIMARÃES, 2006).

Diniz et al. (2009) listam algumas razões pelas quais justifica-se a adoção das tecnologias de informação de forma intensiva e estratégica por parte dos governos, como o uso intensivo das TICs pelos cidadãos, empresas privadas e organizações não governamentais, a migração da informação para mídias eletrônicas e serviços online, o avanço e universalização da infraestrutura pública de telecomunicações e da internet, e o próprio movimento de reforma do Estado, da modernização da gestão pública e da necessidade de maior eficiência do governo . Para 
os autores, como consequência, os programas de governo eletrônico estão associados a temas como desempenho, eficiência, eficácia, transparência, mecanismos de controle, qualidade do gasto público e prestação de contas, relacionados ao processo de modernização da gestão pública.

Nesta mesma perspectiva, Medeiros e Guimarães (2006) apontam outros aspectos que de alguma forma incentivaram o surgimento do governo eletrônico, quais sejam: a) a necessidade das administrações aumentarem sua arrecadação e melhorar seus processos internos, e b) as pressões da sociedade para que o governo otimize seus gastos e atue, cada vez mais, com transparência, qualidade e de modo universal na oferta de serviços aos cidadãos e organizações em geral.

Ainda nesse contexto, o que se sabe é que no Brasil muitos órgãos dos três Poderes têm utilizado portais da web tanto como forma de disponibilização de serviços e publicação de informações quanto como caminho para que o cidadão possa entrar em contato direto com os órgãos, sempre de forma participativa (SILVA; RUE, 2015). Essa é uma lógica seguida por muitos países, que têm ao longo dos anos concentrando esforços para aumentar suas aberturas e transparência para a sociedade como um todo, enxergando no governo eletrônico uma possibilidade eficiente e eficaz para melhorar a transparência pública e reduzir a corrupção (LUPU; LAZAR, 2015; SARRAYRIH; SRIRAM, 2015).

Diante das questões acima levantadas, destaca-se o papel do governo eletrônico de promoção da transparência, aumentando a responsabilidade dos governos por meio da divulgação de uma quantidade maior e de maior qualidade de informações importantes, o que incita os cidadãos e empresas a questionarem decisões arbitrárias e procedimentos excessivos (ELBAHNASAWY, 2014). Assim, a presença dos governos na Internet visa tornar o aparato administrativo menos aparente de forma presencial, mas, ao mesmo tempo, mais próximo do cidadão e mais eficiente na realização de seus objetivos, utilizando, para isso, técnicas e sistemas de informação e comunicação (MEDEIROS; GUIMARÃES, 2006).

Nesse sentido, segundo Sun, Kun e Shih (2015), o padrão utilizado no governo eletrônico descreve como os governos trabalham, compartilham informações e prestam serviços às partes interessadas, seja internas ou externas, resultando em benefícios que incluem a redução da corrupção, maior transparência, maior comodidade, receitas superiores, e menores custos. Dessa forma, desenha-se um modelo de governo que se baseia na utilização das TICs para fornecer serviços públicos integrados, para amplificar a participação e a transparência, e para melhorar as políticas públicas de gestão (LAIA et al., 2011).

Contudo, Oliveira e Raminelli (2014) alertam que esse modelo de governo que preza pela modernização dos serviços e da gestão pública por meio de ferramentas tecnológicas apresenta alguns desafios para a sua plena execução, já que nem sempre a utilização das TICs contemplam totalmente os anseios populares. Os autores questionam se esta é uma iniciativa que se mantém apenas como uma "vitrine" do Governo, apresentando seus conteúdos sem qualquer participação, ou se realmente 
existe uma interação, como por meio de manifestações dos usuários nas referidas páginas.

Ademais, Medeiros e Guimarães (2006) também chamam a atenção para o fato de que os supostos benefícios do governo eletrônico só têm sentido se o público-alvo de suas ações tiver condições de acesso à internet, assim como capacitação para usufruir das informações e serviços ofertados pelo poder público. Segundo os autores, diante da realidade brasileira, marcada por grandes desigualdades sociais, infraestrutura de telecomunicações que ainda não alcança de modo igualitário todo o território nacional, e um baixo nível de educação da população, corre-se o risco de que as possíveis vantagens do governo eletrônico fiquem restritas a uma pequena parcela da população.

Diante de todo o exposto, considera-se que a partir dos portais dos governos os indivíduos podem não apenas acessar de maneira mais transparente as informações públicas, mas também exercer de modo mais efetivo o controle social, colocando o Governo Eletrônico como algo que vai além da modernização tecnológica administrativa (SILVA; RUE, 2015). Nesse cenário, é certo que o uso das TICs originam novos direitos e garantias, questões estas que, no Brasil, se expressam por meio da Lei de n० 12.527, de 2011 (BRASIL. Presidência da República, 2011), a Lei de Acesso à Informação, que prevê maneiras de garantir que o conteúdo de interesse público seja amplamente difundido entre os cidadãos, a fim de que se mantenham sólidos os princípios de democracia e transparência (OLIVEIRA; RAMINELLI, 2014). Os principais aspectos e implicações da referida lei serão tratados na seção a seguir.

\subsection{Lei de acesso à informação}

O uso intensivo das Tecnologias de Informação e Comunicação tem criado um ambiente em que o acesso à informação nunca foi tão fácil quanto na sociedade atual, contudo, ainda que essa seja uma realidade para muitas áreas, sabe-se que há diversos entraves quando se trata de informações que estão sob posse do governo (BERNARDES; SANTOS; ROVER, 2015). É nesse cenário que surge a Lei de Acesso à Informação (LAI), que oportuniza que qualquer cidadão requeira informações acerca de dados governamentais (desde que não sigilosos), assim como determina que a Administração Pública apresente todos os documentos de interesse público, preferencialmente fazendo uso das TICs (OLIVEIRA; RAMINELLI, 2014).

Para Joffily (2012), a Lei de Acesso à Informação, aprovada em novembro de 2011, constitui uma novidade no que se refere à clássica dicotomia entre o direito coletivo à informação e o direito individual de privacidade, assim como seu texto é, inegavelmente um avanço em matéria da legislação de acesso aos arquivos, atendendo a um apelo social crescente pela transparência governamental.

Já para Bernardes, Santos e Rover (2015), a LAI aparece como um instrumento fundamental para efetivação dos direitos cidadãos, na medida 
em que dispõe sobre procedimentos e prazos a serem observados pelos órgãos/entidades públicas a fim de assegurar o direito fundamental de acesso à informação.

Em termos gerais, a LAI dispõe sobre os procedimentos a serem observados pela União, Estados, Distrito Federal e Municípios, com o fim de garantir o acesso a informações, estando dividida em seis capítulos, detalhando a quem se direcionada, como se darão o acesso e a divulgação das informações, a forma como requerer junto aos órgãos e entidades, os documentos sigilosos não passíveis de requerimento e as responsabilidades em caso de negativa de informações ou de tratamento indevido de informações sigilosas ou pessoais, tudo isso durante seus quarenta e sete artigos (BRASIL. Presidência da República, 2011).

Assim, a Lei de Acesso à Informação possui claramente dispositivos que reforçam a obrigação dos governos em utilizar meios eletrônicos para divulgar informações, como uma forma de prestar contas dos atos praticados, contendo, inclusive, algumas exigências que estão contempladas na Lei de Responsabilidade Fiscal, de maio de 2000, assim como na Lei da Transparência, de maio de 2009, ampliando as características no que se refere à prestação de contas (RAUPP; PINHO, 2014).

Nesse contexto, as principais inovações da LAI para a administração pública, embora pareçam pequenas, são tão importantes quanto as referentes ao sigilo, já que a lei implica inovações referentes ao modo de elaboração dos requerimentos de informação, à tramitação dos requerimentos, assim como a estipulação de prazos e penalidades para o descumprimento (PAES, 2011). Além disso, o atendimento das diretrizes estabelecidas pela referida lei, além de facilitar o acesso à informação, agregar representatividade, aumentar e intensificar os níveis de interação entre os cidadãos e seus representantes, também pode ser vantajoso para os próprios órgãos/entidades governamentais, já que tende a diminuir a demanda dos pedidos de acesso, minimizando o trabalho e os custos de processamento e gerenciamento das solicitações de informações (BERNARDES; SANTOS; ROVER, 2015).

Oliveira e Raminelli (2014) destacam que é possível perceber ao longo das últimas décadas que os Estados democráticos têm caminhado em direção da transparência por parte dos governos, algo que se tornou fundamental diante da necessidade de acesso à informação pelo cidadão. Nesse sentido, os autores acrescentam que para o Brasil, a Lei de Acesso à Informação representa um importante meio de impor a todos os órgãos da Administração Pública, em sentido amplo, os procedimentos a serem seguidos, na intenção de garantir o acesso a informações, algo agora constitucionalmente previsto.

Logo, considerando as questões aqui levantadas, considera-se que, ao estabelecer esse marco regulatório, o Brasil dá um importante passo em direção à consolidação e ao amadurecimento do processo democrático, passando da cultura do segredo para a do acesso, e tornando a 
informação como regra e o sigilo como exceção (BERNARDES; SANTOS; ROVER, 2015).

\section{Procedimentos metodológicos}

Este estudo objetivou avaliar a conformidade, em relação à Lei de Acesso à Informação (BRASIL. Presidência da República, 2011), dos sítios eletrônicos de prefeituras do Estado do Rio Grande do Norte. Neste sentido, esta investigação pode ser classificada como exploratóriodescritiva, pois busca mais informações sobre um determinado assunto estudado (CERVO; BERVIAN; SILVA, 2007), e objetiva a descrição de algo (MALHOTRA, 2006), em que os fatos são observados, registrados, analisados, classificados e interpretados, sem que o pesquisador interfira neles (ANDRADE, 2007).

Para a coleta de dados, realizada em junho de 2015, foi utilizada a pesquisa bibliográfica para o levantamento de estudos publicados, com o objetivo de analisar posições diversas em relação ao assunto (GIL, 2010), e para o levantamento das informações disponibilizadas pelas prefeituras avaliadas, obtidas através da pesquisa exploratória em seus sítios eletrônicos.

Já os sítios a serem avaliados foram selecionados com base no levantamento de todos os entes públicos brasileiros participantes do Brasil Transparente (BRASIL, 2015), um programa da Controladoria Geral da União (CGU) que tem o objetivo de apoiar à implementação da Lei de Acesso à Informação e incrementar a transparência pública. Assim, de acordo com o mapa de adesão ao Brasil Transparente, 59 entidades do Rio Grande Norte aderiram ao programa, das quais 52 são prefeituras municipais. Dentre as 52, uma delas não possui sítio eletrônico, a prefeitura da cidade de São Vicente, que possui menos de 10.000 habitantes e por esse motivo é dispensada por lei da divulgação obrigatória na internet (BRASIL. Presidência da República, 2011).

Além disso, as prefeituras de algumas cidades que aderiram ao Programa e atendiam todos os requisitos para fazer parte da pesquisa foram retiradas da avaliação por um dos seguintes motivos: i) não possuírem sítios na internet; ii) sítios fora do ar; e iii) não possuírem nenhuma área nos sítios destinada a divulgação de informações. Logo, foram avaliados um total de 46 sítios eletrônicos das seguintes prefeituras: Bom Jesus, Marcelino Vieira, Pendências, Santana do Seridó, Tibau do Sul. Dessa forma, das 52 prefeituras iniciais, apenas as de 46 cidades fizeram parte da amostra e foram avaliadas no presente estudo, quais sejam: Acari, Assú, Afonso Bezerra, Alto do Rodrigues, Arez, Baía Formosa, Boa Saúde, Bodó, Caicó, Canguaretama, Carnaúba dos Dantas, Carnaubais, Cerro Corá, Cruzeta, Currais Novos, Equador, Espírito Santo, Florânea, Goianinha, Ipueira, Jardim de Angicos, Jundiá, Lagoa Nova, Lagoa Salgada, Montanhas, Monte Alegre, Natal, Nísia Floresta, Ouro Branco, Parelhas, Passa e Fica, Passagem, Porto do Mangue, Riachuelo, Santana dos Matos, São Fernando, São João do Sabugi, São José do 
Seridó, São Pedro, São Rafael, São Tomé, Serra Negra do Norte, Serrinha, Tenente Laurentino Cruz, Timbaúba dos Batistas, e Vila Flor.

$\mathrm{Na}$ análise dos dados, foi adotada a técnica de análise de conteúdo (BARDIN, 2011). Esta técnica consiste em um conjunto de ferramentas de análise das comunicações, que e utilizam de procedimentos sistemáticos e objetivos de descrição dos conteúdos das mensagens através de três passos básicos: a pré-análise, a exploração do material e o tratamento dos resultados por meio de inferência e interpretação (BARDIN, 2011). Assim, na fase de pré-análise, foram organizados todos os dados obtidos através da pesquisa bibliográfica nos estudos da área, assim como dos sítios eletrônicos das prefeituras para, em seguida, na fase de exploração, serem examinados para a definição de categorias de análise.

Portanto, para avaliar a conformidade dos sítios eletrônicos dessas prefeituras, baseando nos segundo e terceiro parágrafos do Artigo 8 da Lei de Acesso à Informação, que dizem que os órgãos e entidades públicas deverão utilizar todos os meios e instrumentos legítimos de que dispuserem, sendo obrigatória a divulgação em sítios oficiais da rede mundial de computadores (internet) (BRASIL. Presidência da República, 2011), foram definidas as seguintes categorias de análise:

i) Ferramenta de busca: Nesta categoria, foi avaliado se o sítio eletrônico continha ferramenta de pesquisa de conteúdo que permita o acesso à informação de forma objetiva, transparente, clara e em linguagem de fácil compreensão;

ii) Formatos de exportação: Nesta categoria, avaliou-se se o sítio eletrônico possibilitava a gravação de relatórios em diversos formatos eletrônicos, inclusive abertos e não proprietários, como planilhas e texto, de modo a facilitar a análise das informações;

iii) Acesso externo: Nesta categoria, foi avaliado se o sítio eletrônico possibilitava o acesso automatizado por sistemas externos em formatos abertos, estruturados e legíveis por máquina;

iv) Estruturação da informação: Nesta categoria, foi avaliado se o sítio eletrônico divulgava em detalhes os formatos utilizados para estruturação da informação;

v) Atualização da informação: Nesta categoria, avaliou-se se o sítio eletrônico mantinha atualizadas as informações disponíveis para acesso;

vi) Instruções para comunicação: Nesta categoria, foi avaliado se o sítio eletrônico indicava o local, assim como instruções que permitem ao interessado comunicar-se, por via eletrônica ou telefônica, com o órgão ou entidade detentora do sítio; 
vii) Acessibilidade para portadores de deficiência: Nesta categoria, avaliou-se se o sítio eletrônico adotava as medidas necessárias para garantir a acessibilidade de conteúdo para pessoas com deficiência.

Por fim, na fase de tratamento dos resultados, foram relatadas as principais inferências e interpretações obtidas, contrastando os principais resultados, por das categorias supracitadas, com o aporte teórico e os estudos da área. Além disso, também utilizou-se de estatísticas descritivas por meio de figuras, na intenção de facilitar a compreensão dos resultados.

\section{Análise dos resultados}

Dando início à análise, a primeira categoria analisada se refere à existência, no sítio das prefeituras, de uma ferramenta de pesquisa de conteúdo que permita o acesso à informação de forma objetiva, transparente, clara e em linguagem de fácil compreensão. Nesse sentido, identificou-se que $89,1 \%$ dos sítios avaliados atenderam positivamente a esta categoria, apresentando alguma ferramenta de busca de conteúdo, como mostra a Figura 1. As únicas prefeituras que não disponibilizam um mecanismo de busca de conteúdo foram as das cidades de Canguaretama, Currais Novos, Lagoa Salgada, Montanhas e Serra Negra do Norte.

De forma geral, esse resultado revela um panorama positivo das prefeituras do Estado do Rio Grande do Norte neste quesito em específico, algo que ganha destaque ao se considerar que permitir e proporcionar o acesso à informação é essencial para a busca de uma sociedade participativa e democrática (OLIVEIRA; RAMINELLI, 2014). Ademais, o estudo de Bernardes, Santos e Rover (2015) ao analisar essa mesma categoria nas prefeituras da região Sul Brasil também encontrou um resultado positivo, em que o mecanismo de busca foi encontrado em $65 \%$ dos sítios eletrônicos.

Figura 1 - Resultados da categoria "Ferramenta de busca"

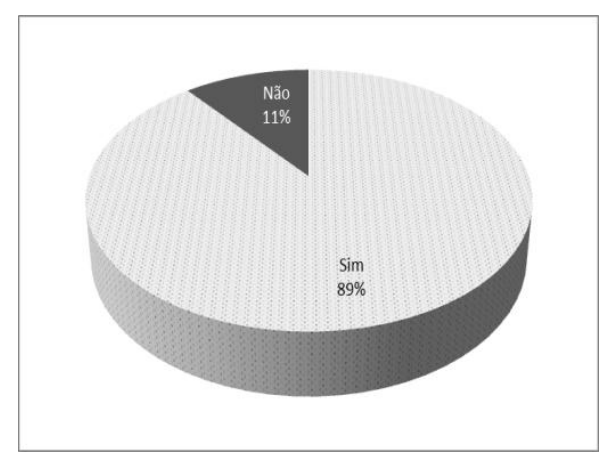

Fonte: Dados da pesquisa.

Já a segunda categoria de análise buscou avaliar se os sítios eletrônicos das prefeituras em questão possibilitavam a gravação de relatórios em diversos formatos eletrônicos, inclusive abertos e não 
proprietários, tais como planilhas e texto. Assim, a Figura 2 revela que $82,6 \%$ das prefeituras avaliadas não tiveram bom desempenho nesse quesito, o que deve ser um alerta, já que tão importante quanto disponibilizar as informações é permitir que elas sejam facilmente analisadas.

Figura 2 - Resultados da categoria "Formatos de exportação"

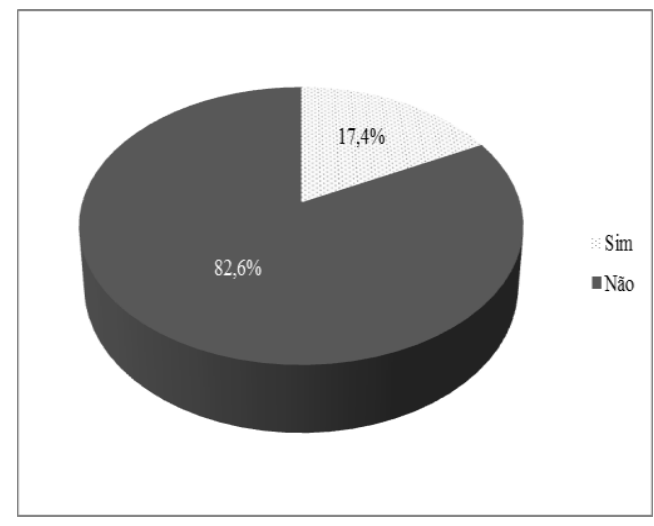

Fonte: Dados da pesquisa.

No que se refere à terceira categoria, que buscou investigar se os sítios eletrônicos das prefeituras possibilitam o acesso automatizado por sistemas externos em formatos abertos, estruturados e legíveis por máquina, é possível observar, de acordo com a Figura 3, que em 78,3\% dos sítios avaliados foram encontradas essa possibilidade. O estudo de Cavalcanti, Damasceno e Souza Neto (2013), por exemplo, também encontrou um bom desempenho ao avaliar esse mesmo aspecto nos sítios eletrônicos das autarquias federais, apresentando resultado positivo em $90 \%$ dos casos.

Nesse sentido, de acordo com o Guia para criação da seção de Acesso à Informação nos sítios eletrônicos dos órgãos e entidades federais, é importante que as entidades ao disponibilizarem a informação considerem que não deve haver obstáculos à leitura dos arquivos por programas de terceiros (BRASIL, 2012). Assim, os resultados positivos encontrados neste e em outros estudos mostram que a tecnologia de informação usada em favor da transparência, com a disponibilização de informações para a sociedade, tem sido utilizada pelas entidades públicas com a preocupação de que não haja barreiras à leitura e, consequentemente, à interpretação dos arquivos.

Figura 3 - Resultados da categoria "Acesso externo" 


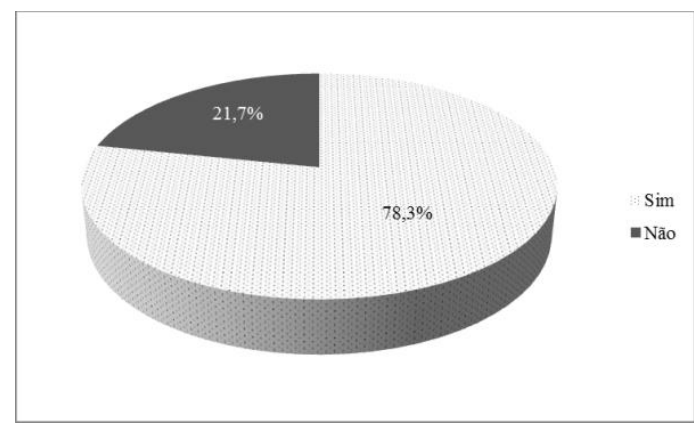

Fonte: Dados da pesquisa.

Já a quarta categoria analisada se refere à divulgação, em detalhes, dos formatos utilizados para estruturação da informação. Conforme mostra a Figura 4, diferentemente dos casos anteriores, não houve um resultado preponderante, já que $50 \%$ dos sítios eletrônicos avaliados realizam a divulgação dos formatos para a estruturação da informação, assim como $50 \%$ dos sítios não faz essa divulgação. De toda forma, esse pode ser considerado um resultado negativo na medida em que 23 sítios eletrônicos, de um total de 46 avaliados, não cumprem esse quesito, utilizado para facilitar a navegação nos sítios por parte dos usuários.

Situação mais alarmante foi encontrada no estudo de Cavalcanti, Damasceno e Souza Neto (2013), já citado anteriormente, em que 93\% da amostra descumpriu com esta recomendação, não disponibilizando nenhum tipo de organograma, manual ou folder que pudesse orientar os usuários sobre como encontrar informações importantes nos sítios eletrônicos.

Contudo, é possível destacar um bom exemplo de sítio eletrônico que dá detalhes de como a informação está estruturada, que é o caso da prefeitura da cidade de Assú. Em seu sítio eletrônico é possível encontrar um mapa das informações disponibilizadas, inclusive com glossário. Esse tipo de estrutura facilita o acesso à informação, e assim como apontado pela literatura, incitar a sociedade como um todo, por meio das informações adquiridas, a questionar decisões arbitrárias e procedimentos excessivos, por exemplo (ELBAHNASAWY, 2014).

Figura 4 - Resultados da categoria "Estruturação da informação"

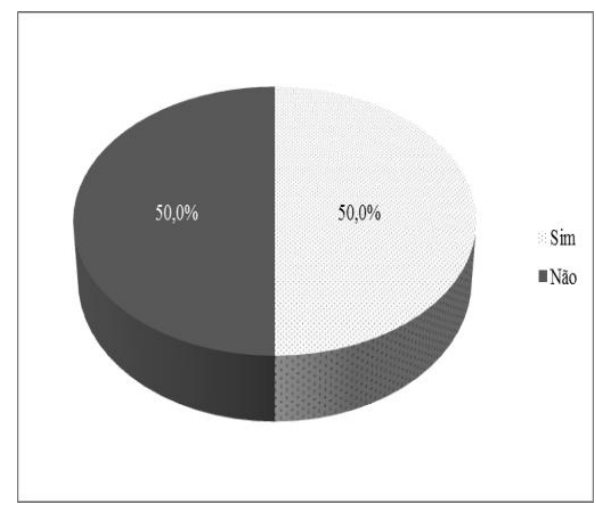

Fonte: Dados da pesquisa. 
A quinta categoria buscou avaliar se os sítios eletrônicos das prefeituras mantêm atualizadas as informações disponíveis para acesso. Por conseguinte, identificou-se que $54,3 \%$ da amostra está cumprindo essa recomendação, como é possível visualizar na Figura 5. Apesar de a resposta positiva aparecer em maior número, considera-se que esse não é um número de destaque, ficando o alerta para as prefeituras do Estado do Rio Grande do Norte no sentido de além de garantir o acesso à informação, ser capaz de disponibilizar dados realmente atuais e que sejam condizentes com a realidade.

Vale destacar ainda que em alguns casos esse quesito não pôde ser avaliado, como os sítios eletrônicos das prefeituras das cidades de Natal, Ouro Branco, Parelhas e Serra Negra do Norte. Isso se deu em decorrência do fato de que esses sítios disponibilizam informações por meio de solicitações dos interessados, o que impede que sejam feitas afirmações acerca da atualização ou não das informações.

Figura 5 - Resultados da categoria "Atualização da informação"

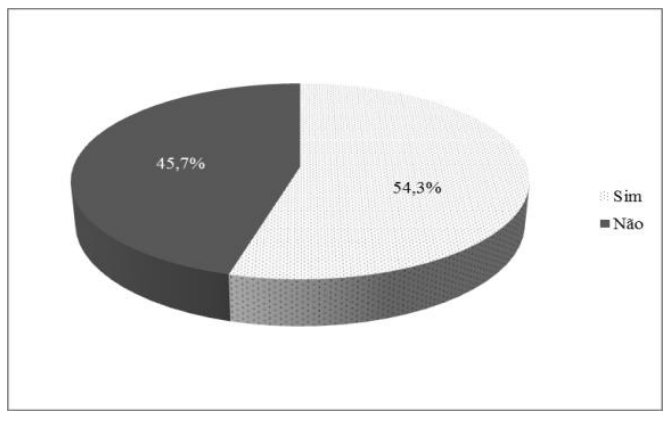

Fonte: Dados da pesquisa.

A sexta categoria analisada trata da indicação nos sítios eletrônicos do local e instruções que permitam ao interessado comunicar-se, por via eletrônica ou telefônica, com o órgão ou entidade detentora do sítio. A Figura 6 mostra um desempenho negativo nesse quesito, com $63 \%$ da amostra não atendendo a determinação feita na Lei de Acesso à Informação. Por outro lado, o estudo de Cavalcanti, Damasceno e Souza Neto (2013), que também avaliou essa categoria nos sítios eletrônicos das autarquias federais encontrou uma situação oposta, em que cerca de $83 \%$ da amostra cumpriu com esta determinação.

Considerando que, conforme discutido na literatura, a Lei de Acesso à Informação apresenta um texto que contribui com o avanço da legislação que garante 0 acesso aos arquivos, de forma a atender a um apelo por transparência por parte dos governos (JOFFILY, 2012), encontrar uma realidade como esta, em que a maioria dos sítios avaliados não faz nenhuma menção sobre o local e como os interessados podem comunicar-se com o órgão ou entidade de interesse, permite 
questionar se essas prefeituras objetivam realmente a participação e interação com os usuários de forma democrática.

Figura 6 - Resultados da categoria "Instruções para comunicação"

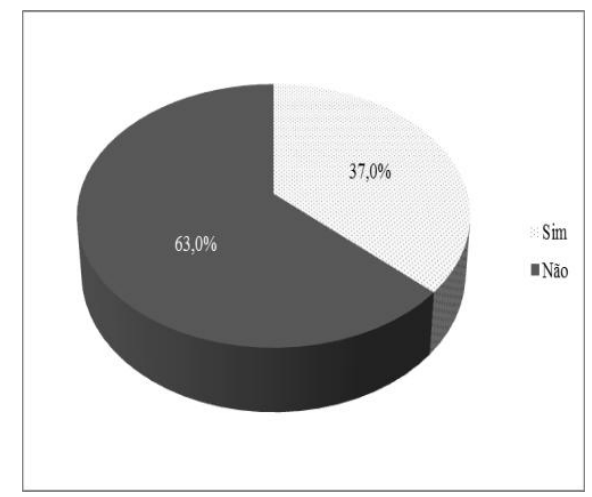

Fonte: Dados da pesquisa.

Finalmente, a sétima categoria analisada analisou se os sítios eletrônicos das prefeituras do Estado do Rio Grande do Norte adotam as medidas necessárias para garantir a acessibilidade de conteúdo para pessoas com deficiência. Nesse sentido, a Figura 7 revela uma péssimo desempenho dos sítios avaliados, 97,8\% deixando de cumprir a legislação, sequer indicando a adoção de tais medidas.

Esta é uma oportunidade de fazer um alerta as prefeituras avaliadas, assim como os demais órgãos e entidades, já que se por um lado as tecnologias de informação e comunicação podem contribuir para a democracia, no caso das pessoas com deficiência essa participação cidadã apenas será efetivada caso as premissas básicas de acessibilidade digital sejam consideradas na implantação do governo eletrônico (SILVA; RUE, 2015).

Figura 7 - Resultados da categoria "Acessibilidade para portadores de deficiência" 


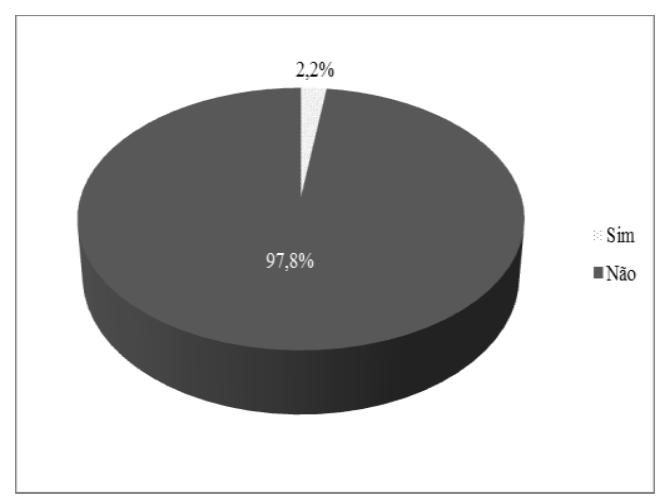

Fonte: Dados da pesquisa.

Em síntese, o panorama criado sobre a conformidade ou não dos sítios eletrônicos de prefeituras do Estado do Rio Grande do Norte em relação à Lei de Acesso à Informação mostra uma realidade em que esses órgãos de alguma forma têm concentrado esforços na disponibilização de informações para a sociedade, algo positivo na busca pela transparência, contudo questões básicas e não menos importantes ainda carecem de atenção, precisando ser melhor desenvolvidas.

A literatura aponta claramente que é de fundamental importância os estados brasileiros sejam capazes de implantar o governo eletrônico preocupando-se não apenas com a simples transposição de serviços físicos para a internet, mas buscando a efetivação da participação política de maneira sofisticada, assim como empregando as tecnologias informacionais com o escopo de propiciar maior abertura à intervenção da sociedade civil na condução da democracia (SILVA; RUE, 2015).

\section{Considerações finais}

O objetivo de avaliar a conformidade, em relação à Lei de Acesso à Informação, dos sítios eletrônicos de prefeituras do Estado do Rio Grande do Norte participantes do programa Brasil Transparente, que objetiva apoiar à implementação da Lei de Acesso à Informação e incrementar a transparência pública, foi alcançado com êxito no presente estudo, apresentando importantes características dos sítios avaliados, assim como apontando aspectos que precisam receber maior atenção.

Além disso, foi realizado um levantamento teórico acerca da importância das Tecnologias de Informação e Comunicação e suas implicações na Administração Pública, assim como os principais aspectos envolvidos no conceito de Governo Eletrônico e da Lei de Acesso à Informação, que vem para regular o relacionamento entre governo e sociedade. Nesse sentido, identificou-se que as temáticas têm ganhado espaço nas discussões, com a publicação de artigos nos últimos anos que, entre outras questões, têm analisado em diferentes realidades ou esferas públicas se a transparência e a participação democrática têm sido proporcionadas pelos sítios eletrônicos. 
Mais especificamente, tratando dos 46 sítios eletrônicos de prefeituras do Estado do Rio Grande do Norte aqui avaliados, identificouse que eles apresentam bom desempenho no que se refere a: existência de ferramentas de pesquisa de conteúdo, permitindo o acesso à informação de forma objetiva, transparente, clara e em linguagem de fácil compreensão; acesso automatizado por sistemas externos em formatos abertos, estruturados e legíveis por máquina; divulgação em detalhes dos formatos utilizados para estruturação da informação, apesar de metade dos sítios ainda não fazer esse detalhamento; e manter atualizadas as informações disponíveis para acesso. Por outro lado, um desempenho inferior foi encontrado nas seguintes categorias: possibilitar a gravação de relatórios em diversos formatos eletrônicos, inclusive abertos e não proprietários, tais como planilhas e texto; o que não facilita a disseminação e análise das informações pelos usuários; indicar local e instruções que permitam ao interessado comunicar-se com o órgão ou entidade detentora do sítio; preceito básico do acesso à informação; e adoção de medidas necessárias para garantir a acessibilidade de conteúdo para pessoas com deficiência.

Esses achados mostram que o governo eletrônico tem sido aplicado pelas prefeituras do Rio Grande do Norte que foram avaliadas, porém com muitos avanços a serem realizados, visto que foram reveladas algumas não conformidades em relação à Lei de Acesso à Informação. Espera-se que a avaliação aqui realizada possa servir como base para iniciativas futuras, e que a participação da sociedade na esfera pública possa realmente ser garantida, com toda e qualquer pessoa acessando os sites governamentais, consultando informações e participando da construção do processo político.

Por fim, trabalhos futuros podem dar continuidade à discussão aqui realizada, replicando-a nos sítios eletrônicos de prefeituras de outros estados brasileiros, assim como realizado a comparação entre os resultados. Ademais, os critérios utilizados também podem ser utilizados para avaliar não só prefeituras, como qualquer outro tipo de autarquia, órgão ou entidade federal.

\section{Referências}

ANDRADE, M. M. Introdução à metodologia do trabalho científico. 8. ed. São Paulo: Atlas, 2007.

BARDIN, L. Análise de conteúdo. São Paulo: Edições 70, 2011.

BERNARDES, M. B.; SANTOS, P. M.; ROVER, A. José. Ranking das prefeituras da região Sul do Brasil: uma avaliação a partir de critérios estabelecidos na Lei de Acesso à Informação. Revista de Administração Pública, v. 49, n. 3, p. 761-792, 2015.

BRASIL. Presidência da República. Lei n. 12.527, de 18 de novembro de 2011. Regula o acesso a informações previsto no inciso XXXIII do art. 5o, no inciso II do $\S 30$ do art. 37 e no $\S 20$ do art. 216 da Constituição 
Federal; altera a Lei no 8.112, de 11 de dezembro de 1990; revoga a Lei no 11.111 , de 5 de maio de 2005, e dispositivos da Lei no 8.159 , de 8 de janeiro de 1991; e dá outras providências. Diário Oficial [da] República Federativa do Brasil, Brasília, DF, 18 nov. 2011. Disponível em: <http://www.planalto.gov.br/ccivil_03/_ato20112014/2011/lei/l12527.ht m>. Acesso em: 16 jun. 2015.

BRASIL. Presidência da República. Controladoria Geral da União. Guia para criação da seção de Acesso à Informação nos sítios eletrônicos dos órgãos e entidades federais. Brasília, 2012. Disponível em: <www.unifesp.br/images/guia_lai.pdf>. Acesso em: 18 jun. 2015.

BRASIL. Presidência da República. Controladoria Geral da União. Escala Brasil Transparente. 2015. Disponível em: <http://www.cgu.gov.br/assuntos/transparencia-publica/escala-brasiltransparente $>$. Acesso em: 16 jun. 2015.

CAVALCANTI, J. M. M.; DAMASCENO, L. M. S; SOUZA NETO, M. V. Observância da lei de acesso à informação pelas autarquias federais do Brasil. Perspectivas em Ciência da Informação, v. 18, n. 4, p. 112-126, 2013.

CERVO, A. L.; BERVIAN, P. A.; SILVA, R. Metodologia científica. 6. ed. São Paulo: Prentice Hall, 2007.

CUNHA, M. A. V. C.; MIRANDA, P. R. M. O uso de TIC pelos governos: uma proposta de agenda de pesquisa a partir da produção acadêmica e da prática nacional. Organizações \& Sociedade, v. 20, n. 66, p. 543-566, 2013.

DINIZ, E. H. et al. O governo eletrônico no Brasil: perspectiva histórica a partir de um modelo estruturado de análise. Revista de Administração Pública, v. 43, n. 1, p. 23-48, 2009.

ELBAHNASAWY, N. G. E-Government, Internet Adoption, and Corruption: An Empirical Investigation. World Development, v. 57, pp. 114-126, 2014.

GIL, A. C. Como elaborar projetos de pesquisa. 5. ed. São Paulo: Atlas, 2010.

JOFFILY, M. Direito à informação e direito à vida privada: os impasses em torno do acesso aos arquivos da ditadura militar brasileira. Estudos Históricos, v. 25, n. 49, p. 129-148, 2012.

LAIA, M. M. et al. Electronic government policies in Brazil: context, ICT management and outcomes. Revista de Administração de Empresas, v. 51, n. 1, p. 43-57, 2011.

LUPU, D.; LAZAR, C. G. Influence of e-government on the level of corruption in some EU and non-EU states. Procedia Economics and Finance, v. 20, p. 365-371, 2015.

MALHOTRA, N. K. Pesquisa de marketing: uma orientação aplicada. 6. ed. Porto Alegre: Bookman, 2006. 
MEDEIROS, P. H. R.; GUIMARÃES, T. A. A institucionalização do governo eletrônico no Brasil. Revista de Administração de Empresas, v. 46, n. 4, p. $1-13,2006$.

OLIVEIRA, R. S.; RAMINELLI, F. P. O direito ao acesso à informação na construção da democracia participativa: uma análise da página do conselho nacional de justiça no facebook. Sequência, n. 69, p. 159-182, 2014.

PAES, E. B. A construção da Lei de Acesso à Informação Pública no Brasil: desafios na implementação de seus princípios. Revista de Serviço Público, v. 62, n. 4, p. 407-423, 2011.

RAUPP, F. M.; PINHO, J. A. G. Prestação de Contas nos Portais Eletrônicos de Assembleias Legislativas: um estudo após a Lei de Acesso à Informação. Revista Gestão e Planejamento, v. 15, n. 1, p. 144-161, 2014.

SANTOS, P. M. et al. Ranking dos tribunais de contas brasileiros: uma avaliação a partir dos padrões web em governo eletrônico. Revista de Administração Pública, v. 47, n. 3, p. 721-744, 2013.

SARRAYRIH, M. A.; SRIRAM, B. Major challenges in developing a successful e government: A review on the Sultanate of Oman. Journal of King Saud University - Computer and Information Sciences, v. 27, n. 2, p. 230-235, 2015.

SILVA, R. L.; RUE, L. A. A acessibilidade nos sites do Poder Executivo estadual à luz dos direitos fundamentais das pessoas com deficiência. Revista de Administração Pública, v. 49, n. 2, p. 315-336, 2015.

SISKOS, E.; ASKOUNIS, D.; PSARRAS, J. Multicriteria decision support for global e-government evaluation. Omega, v. 46, p. 51-63, 2014.

SUN, P. L.; KU, C-Y.; SHIH, D. H. An implementation framework for EGovernment 2.0. Telematics and Informatics, v. 32, p. 504-520, 2015. 